\title{
ПЕРСПЕКТИВЫ СТАНОВЛЕНИЯ ГЛОБАЛЬНОГО ИНТЕЛЛЕКТА: ОТ СФЕРЫ РАЗУМА В ПРОСТРАНСТВО МУДРОСТИ
}

В первой половине прошлого века российский ученый академик В.И. Вернадский и два французских ученых - П.Тейяр де Шарден и Э.Леруа выдвинули идею становления сферы разума - ноосферы в качестве главного направления дальнейшего развития человечества, которое должно рационализировать цивилизационный процесс, обеспечить выживание цивилизации.

В.Вернадский предсказал, что научная мысль обретёт «планетный» (глобальный) характер. И конкретные очертания этого предсказания мы видим как в ныне происходящих глобальных процессах в мире и их осмыслении, так и в предвидении и исследовании будущих социальных и социоприродных эволюционных процессов. В.И. Вернадский сейчас видится в качестве мудрого мыслителя глобальной эпохи, которая в перспективе становится также эпохой ноосферы (Ильин, Урсул 2013, Урсул 2013).

Концепции сферы разума, или ноосферы, которые были предложены их основоположниками, существенно различались между собой. Однако все они имели некоторое общее содержание и исследовательскую ориентацию - веру в силу разума (не только человеческого) и представление интеллекта в его различных формах в качестве главного движущего механизма последующей уже «целесообразно-разумной» эволюции. Хотя термин «ноосфера» не употреблялся К.Циолковским, тем не менее, он также говорил о роли разума во Вселенной, полагая, что мысль оказывается не только геологическим фактором (о чем писал В.И. Вернадский), но и станет решающим фактором в эволюции космоса.
Идея об усилении роли разума в развитии общества не является достоянием лишь конца тридцатых годов XX века, когда французский ученый и философ Э.Леруа, а затем его соотечественник П.Тейяр де Шарден и В.Вернадский стали использовать понятие «ноосфера». Причем В.Вернадский признавал приоритет упомянутых своих коллег во введении термина «ноосфера». Так, во фрагменте «Несколько слов о ноосфере» он отмечает: «Приняв установленную мною биогехимическую основу биосферы за исходное, французский математик и философ бергсонианец Е. ЛеРуа в своих лекциях в Коллеж де Франс в Париже ввел в 1927 г. понятие «ноосферы» как современной стадии, геологически переживаемой биосферой. Он подчеркивал при этом, что он пришел к такому представлению вместе со своим другом, крупнейшим геологом и палеонтологом Тельяром де-Шарденом, работающим теперь в Китае» (Вернадский 1991: 241).

Не стоит жестко привязывать ноосферные идеи, концепции и движения к термину «ноосфера», имея также в виду, что эти идеи и течения с самого начала своего генезиса является международными, теперь даже глобальными. Роль и место разумного начала в социальной деятельности определяет становление ноосферной идеи, начиная с античности, а тем более, когда стали применяться такие термины как «царство разума» (просветители), «мир разума» (мондиалисты), информационное общество, общество знания или же принятый в России термин «ноосфера». Поэтому «ноосферное движение» оказывается более широким, чем те иссле- 
дования, которые используют ставший уже традиционным термин «ноосфера».

Когда речь идёт о феномене ноосферы и становлении ноосферной цивилизации, то фактически имеется в виду наше общее будущее, а точнее - один из возможных и наиболее желаемых его сценариев и основных целей будущего перехода к глобальному устойчивому развитию. Здесь мы вступаем в сферу исследования или осознания будущего, как оно нам представляется на основе современной науки и интуиции того или иного автора. Превращение человечества в ноосферную цивилизацию предполагает, что культура как информационный феномен станет решающим фактором развития социальной ступени эволюции. Главной составляющей ее дальнейшей эволюции станут информация и информационные процессы, реализуется опережающее развитие естественных и искусственных интеллектуальных процессов и духовной культуры (прежде всего, науки, управления, образования).

Хотя здесь далее развиваются основополагающие идеи В.Вернадского о ноосфере, но вместе с тем идёт определенное расширение концептуального видения феномена ноосферы до эволюционно-космических масштабов. Речь будет идти не только о том, что биосфера создает возможности становления сферы разума, но и о том, что появление ноосферы обусловлено глобальной эволюцией во Вселенной. По сути дела, ноосферогенез как грядущий глобальный процесс становления сферы разума в перспективе оказывается тем этапом глобальной эволюции мироздания, которая будет реализоваться в социоприродной форме вначале на Земле, а затем и за ее пределами.

Становление ноосферы представляется не только как неизбежный этап на пути планетарного развития, но и как продолжения глобальной эволюции, её основной траектории - так на- зываемой супермагистрали, характеризующейся ростом сложности и накоплением информационного содержания всё более высоких структур и систем в ходе их самоорганизации. Ноосферный этап глобальной эволюции наступает, когда в цивилизации появляется не только огромное информационное содержание, но и появляется новое качество информационно-интеллектуальных процессов, особенно появления свойства опережения глобально-коллективным интеллектом своего бытия.

Вместе с тем общепланетарный характер становления сферы разума определяется не только несколькими развернувшимися мегатенденциями, скажем, глобализацией, информатизацией или биосферно-экологическими процессами, а фактически всеми основными составляющими системы человеческой деятельности как глобального цивилизационно-культурного развития. В связи с этим уместно обратить внимание, что в своей «философии всеединства» русский философ В.Соловьёв обосновывал представление о том, что разум может разъединять людей, тогда как мудрость должна стать основой их соединения в целостную систему. Его идея всеединства как в определённой степени философское предвидение ныне развёртывающегося процесса глобализации и даже ноосферогенеза, выражает наличие взаимосвязи и взаимопроникновения составляющих элементов мирового бытия. их органическое единство, при сохранении индивидуальности. Не углубляясь в эту концепцию, можно полагать, что не столько разум, сколько мудрость должна стать той интеллектуально-культурной основой, на которой будет строиться сфера или даже более широко пространство мудрости.

Впрочем, такое отношение к мудрости характеризует не только философию всеединства, но философию вообще, особенно на ранних стадиях её становления. Ведь этимологически сло- 
во “философия» (др.-греч.фь означало "любовь к мудрости». Мудрость не случайно появилось на ранней стадии эволюции философии, представляя собой некоторое синкретическое понятие, но затем, как и философия, оно начало расчленяться и сейчас свелось к рациональности, или даже к экономической рациональности.

Сейчас понятно, что мудрость не может сводиться ни к разуму, ни к рациональности, это системное и более фундаментальное для общечеловеческого сознания понятие, включающее в себя рациональность, в том числе и научную рациональность, в качестве одной из составляющих. Мудрость опирается на научное знание, на знание в более широком смысле и, конечно, на здравый смысл, но оказывается гораздо более широким и системным понятием, а не характеристикой собственно научных знаний. Мудрость как глубокий и всесторонний разум, опирающийся на жизненный опыт, даже стали больше относить к сфере нравственности и этики, где знания индивида уже соединяются с ценностями. Мудрость предстает в качестве единства творческого мышления с высокой нравственностью и гуманизмом, что придает знанию смысл и формирует жизненную ориентацию индивида, усиливая его ответственность за будущие действия.

Именно мудрости приписывают высший принцип (или закон), высказанный ещё Конфуцием: «Делай другим то, чего ты желаешь себе». Эта же идея составила категорический императив Канта: «... поступай только согласно такой максиме, руководствуясь которой ты в то же время можешь пожелать, чтобы она стала всеобщим законом» (Кант 1965: 260).

Особое значение в плане темы статьи следует обратить внимание на то, что мудрость дает возможность предвидения возможного развития процессов и событий. Способность ви- деть будущее, умение прогнозировать ход событий относят едва ли не к наиболее важной характеристике феномена мудрости. Однако, речь, скорее всего, идет о соблюдении принципа темпоральной целостности в особой форме: знать прошлое, понимать настоящее, осознавать будущее и принимать адекватные решения, учитывая возможные их последствия. Существуют и другие характеристики и черты мудрости, на которых мы специально не будем останавливаться (Назаров 1993).

Можно также ожидать, что по мере созидания сферы разума поэтапно, насколько возможно, к ней будут добавляться и черты феномена мудрости. Именно это предположение (гипотеза) о направленности ноосферогенеза в пространство мудрости дало повод для автора вынести его в подзаголовок статьи.

Важной особенностью ноосферной концепции В.Вернадского является выяснение роли разума не только в жизни общества, но через него в эволюции биосферы (особенно геологической и биосферной эволюции). В принципе идея ноосферогенеза как становления сферы разума отличается от идеи ноогенеза, которая была предложена П.Тейяром де Шарденом (Тейяр де Шарден 1987) тем, что в первом случае ноогенез рассматривается совместно с трансформациями окружающей его среды. Это напоминает идею биосферы, теория которой была существенно развита Вернадским, когда биота включается в сферу взаимодействующего с ней косного вещества (Вернадский 2004). И такая идея оказывается в эволюционном плане более адекватной, поскольку развитие социума, тем более прогрессивное, в силу синергетических соображений следует рассматривать именно как разнонаправленное соразвитие, причём желательно, как коэволюцию системы совместно с природной средой, за счет которой оно происходит. Тем самым речь должна идти именно о ста- 
новлении сферы разума как ноосферогенезе, а не о ноогенезе, как об этом пишет в своей книге «Феномен человека» П.Тейяр де Шарден, уделяя внимание в основном развитию сознания, процессу интеллектуализации материи в ходе эволюции. Ноосферогенез - более широкое и адекватное понятие, чем ноогенез, поскольку он касается не только духовно-интеллектуальной составляющей ноосферы, но и материальной, не только культурно-информационной, но и вещественно-энергетической компоненты - и это существенное отличие точки зрения В.Вернадского от его уже упомянутых коллег.

Такое пространственное расширение сферы разума за пределы социума имеет определённые теоретико-методологические основания: ведь ограничение сферы разума только обществом вовсе не означает, это последнее ведёт себя разумно по отношению к природе. И это демонстрирует современная глобально-экологическая ситуация, которая стремительно ухудшается в современной модели неустойчивого развития (GEO-5 2012). Сейчас же цивилизация, формально состоящая из более, чем двух сотен суверенных государств, и 7 млрд автономных индивидов, судорожно «цепляясь» за старую модель развития, неуклонно движется к своему трагическому финалу - глобальной социальноэкологической катастрофе, - и в этом трагическое противоречие современного неустойчивого развития.

Последнее десятилетие прошлого века внесло важные коррективы в понимание процесса становления ноосферы. Ноосфера - не просто сфера распространения человека разумного разумного (даже наименование которого «Homo sapiens» сейчас стало подвергаться серьезным сомнениям и дискуссиям (Прозоров 2012). Ноосфера, как полагал В.Вернадский, представляется как «новое геологическое явление на нашей планете. В ней впервые человек становится крупнейшей геологической силой. Он может и должен перестраивать своим трудом и мыслью область своей жизнью, перестраивать коренным образом по сравнению с тем, что было раньше. Перед ним открываются всё более и более широкие творческие возможности» (Вернадский 1991: 241). Здесь ученый рассматривает ноосферогенез как продолжение биосферно-геологической эволюции, в которой крупнейшей геологической силой выступает не только биота, но уже и человечество.

Однако вряд ли имеет смысл называть ноосферой прошлую или современную социосферу, где самым совершенным типом разума обладает лишь отдельный нормальный индивид. Это будет лишь простое переименование социосферы в ноосферу, которое никак не изменяет степень разумности всего человечества, которое по-прежнему будет стремиться к своей экологической, ядерной или иной форме стихийно-коллективного, как теперь уже ясно, глобального самоубийства. Важно сформировать принципиально новый - не только индивидуальный, но и качественно более высокий, уже общечеловеческий - глобально-ноосферный интеллект, способный вывести цивилизацию из кризиса, предотвратить возможные планетарные и космические катастрофы. Грозящие человечеству опасности и угрозы, особенно глобально-космического характера, заставляют развиваться человеческому интеллекту, принимать глобальные формы существования и функционирования.

Ноосфера (от греч. vóо - "разум" и бфатра - «шар») видится как гипотетическое будущее состояние (и вместе с тем дальнейший глобально-космический процесс) общества и его взаимодействия с природой, в котором приоритетное место будет занимать коллективный общечеловеческий разум, именуемый ноосферным интеллектом, направляющий эволюцию цивилизации в прогрессивно-поступательном и бе- 
зопасном направлении. Ныне имеющийся, но трудно определимый совокупный интеллект всего человечества гораздо менее эффективен среднего индивидуального интеллекта, если иметь в виду здорового нормального человека, а не больного либо девиантного индивида, стремящегося к суициду. Помимо прочего, это связано с отсутствием необходимых взаимосвязей между частями мирового социума (которые имеются на уровне индивида), и которые появляются в процессе глобализации, которая в этом смысле выступает как одно из направлений формирования ноосферного интеллекта. Вот почему «коллективизация» разума вплоть до обретения им нового качества и целостности в процессе будущего ноосферогенеза преследует цель распространить более рациональное (эффективное) поведение на всю человеческую цивилизацию и ее взаимодействие с природой: «лучшее понимание и переход от понимания к действию - именно такую цивилизацию мы охарактеризовали бы как более разумную» (Вайцзеккер, Ловинс Э., Ловинс Л. 2000: 353).

Если выйти за темпоральные пределы происходящего в последние десятилетия или даже столетия в более широкие временные периоды, то можно совершенно по-иному представить глобальные процессы и формирующиеся благодаря им глобальные системы (структуры). Эволюционное видение позволяет выявить определенные направленные трансформации всех глобальных процессов, создаваемых с их помощью структур (имеющих не только глобально-пространственные масштабы, но и общемировое значение) и даже появление новых, в основном как результат деятельности человечества и развертывания социоприродного этапа эволюции. С точки зрения эволюционного подхода в глобальных исследованиях все глобальные процессы и системы могут иметь прогрессивную, регрессивную либо иную направленность развития.
Существуют различные методы измерения направления и уровня (степени) развития материальных систем, среди которых наиболее универсальным и пока наиболее эффективным и инвариантным является информационный критерий развития (Урсул 1972). Информация, повидимому, играет гораздо более существенную роль в развитии мироздания, чем это представляется в настоящее время. Вероятно, все согласны с тем, что роль информации и информационного подхода все больше возрастает в научном познании. Но важно, понимая и принимая эту тенденцию, выявить - какое же место займет информация среди наиболее фундаментальных категорий науки, если не современной, то будущей науки.

Ведь, с одной стороны, философия претендовала и пока еще претендует на то, чтобы ее категории (может быть, и не все) играли лидирующую и генерирующую роль в научном познании. Но не только она, но и другие, особенно наиболее развитые науки, претендующие на роль лидера в науке в целом, и, прежде всего физика, также считают свои основные понятия самыми важными и фундаментальными. Однако сейчас, вначале XXI века, после немногим более полувекового развития науки об информации, оказалось, что и информация может претендовать, не только на роль концептуального лидера, но и самое основное ее понятие считается чуть ли не самым важным понятием не только науки, но всей когнитивной системы цивилизации. Но не только цивилизации, но и в принципе, всего мироздания (Ллойд 2013).

Проблема информации, которая возникла немногим более полувека тому назад, играет все большую роль в науке благодаря интенсивному развертыванию процесса информатизации и становлению глобального информационного общества. Информационный подход к глобальной эволюции реализовался в основном в той 
исследовательской парадигме, которая исходит из атрибутивного характера информации, придавая ей такой же онтологический статус, как и энергии. В рамках этой парадигмы принимается принцип неразрывной взаимосвязи энергии и информации, т.е. энергетические процессы оказываются в той или иной степени и информационными процессами (и наоборот).

На определенной стадии эволюции во Bceленной на первый план выступают либо энергетические, либо информационные процессы, однако с ростом уровня организации и сложности систем роль информации и информационного критерия развития существенно возрастает.

Если бы ранее не была бы высказана идея ноосферы, она все равно появилась бы, поскольку формирование такого уникального информационного и в тоже время - социоприродного образования обусловлено самой информационной сущностью социальной ступени развития материи, что отличает ее от информационных характеристик биологической ступени (Урсул 2011). Важно обратить внимание на то, что одной из важнейших особенностей биологической информации является то, что она в основном накапливается, хранится и передается последующим поколениям эндогенно - на генетическом уровне. Конечно, в ходе обучения в процессе онтогенеза появляется и внегенетическая информация, но потомкам она не передается. Биологическая ступень эволюции внутри себя как бы создала информационные ограничения, которые определили и ограничили ее место на супермагистрали глобальной (универсальной) эволюции. Следующая за ней социальная ступень эволюции для себя снимает эти ограничения, благодаря чему получает возможность дальнейшей ускоренной самоорганизации, обретая новые, более эффективные и безопасные способы существования и взаимодействия с окружающей средой.
Наряду с генетическими механизмами эволюции информационных процессов в биологических системах, возник и развернулся связанный с ними процесс цефализации, который оказался решающим для выхода особых гоминид из мира биоты в мир социальный. Процесс цефализации стал тем важным звеном на глобально-эволюционной траектории, который показывает, как произошел (и по какому пути пошёл) переход от основного эндогенно-генетического механизма накопления информации к экзогенно-культурной форме этого продолжения супермагистрали эволюции. В.Вернадский и П.Тейяр де Шарден особо выделяли в эволюции процесс цефализации, на вершине которого оказался человек. Тем самым ноосферогенез оказывается предвидимым этапом предшествующей глобально-универсальной эволюции, которая будет реализоваться в социоприродной форме, вначале на планете Земля, а затем и за ее пределами, как высшее достижение социокультурного развития человеческой цивилизации.

Именно благодаря действию экзогенного информационно-культурного вектора дальнейшей поступательной эволюции, биологическое развитие человека уходит на периферийное место, хотя полностью не останавливается. За последние сорок тысяч лет геном человека изменился менее, чем на сотые доли процента, и человечество как биологический вид практически уже не эволюцинирует (либо эволюционирует весьма медленно) в различных природных условиях планеты в отличие от того, как это происходило с его предками в «биологическую эру». Это произошло потому, что «человек культурный» - и он же «гомо сапиенс» - передал основную функцию накопления информации в социосфере от своего организма внешнему для него, но имманентно с ним связанному эволюционному процессу культурогенеза. 
Главным процессом накопления информации в социальной ступени выступает внеорганизменный и внегенетический информационный процесс, тогда как в биологической ступени такое накопление происходит в основном на генетическом уровне. Разумеется, в социальной ступени эволюции также происходят генетические процессы накопления и передачи информации, поскольку человек - не только социальное разумное существо, но и биологическое. Однако не они определяют основные информационные процессы в обществе, которые скрываются в культуре как основном информационном процессе как главной характеристике социальной эволюции. Наличие надбиологических механизмов, т.е. программ, кодов, алгоритмов и т.д. действительно играет важнейшую роль в развитии общества, выражая не только его отличие от биологической ступени, но фактически глубинную информационно-культурную природу социальной ступени.

Исходя из подобного предположения, многие важные тенденции социального развития можно объяснить, исходя из того, что природа социального заключена именно в культуре. Именно культуру характеризует экзогенно-внегенетический принцип накопления, передачи и преобразования информации. Эта информация заимствуется из окружающей человечество среды - как земной, так и космической (согласно синергетике) и, кроме того, требует все больших пространств и объектов этой среды, как для накопления культурной информации, так и для отвода за пределы социума отходов (энтропии в широком смысле).

На уровне становления и развития общества в эволюционной информодинамике наступают качественно-нелинейные изменения. А именно: происходит «вынос» ряда информационных процессов (накопления, хранения, преобразования и т.п. информации) за пределы струк- турного элемента ступени. Это специфическая и сущностная характеристика социальной ступени эволюции, выражающая ее принципиальное отличие от предыдущей - биологической ступени. Накопление информации и её преобразование продолжается в основном не в структурной единице соответствующей ступени, а вне ее, что требует освоения внешнего окружающего пространства и преобразования находящихся в нем объектов для превращения их в феномены культуры - артефакты и смыслы.

Передача культурной информации также требует использования пространства и материальных объектов вне организма составляющих общество людей и активного участия в этом процессе их сознания. Это также означает, что в отличие от предыдуших ступеней развития человечество начинает расширять сферу своего распространения как на Земле, так и в космосе не только для получения вещественно-энергетических ресурсов, но, прежде всего, для получения негэнтропии из окружающей среды, продолжения своих информационно-самоорганизационных процессов.

Однако дело не только в том, что экзогенный способ накопления и преобразования информации, принявший сейчас глобальные и космические масштабы, расширяет по планете и за её пределами социальную ступень развития. Внегенетический способ освоения информации оказал существенное влияние на темпы социальной эволюции, значительно ускорив социально-информационные процессы по отношению к процессам информационно-биологическим, а тем более к темпам эволюции предшествующих ступеней и уровней известного нам мироздания. Экзогенно-культурный способ продолжения социально-информационных процессов на супермагистрали глобальной эволюции ускоряет их течение, поскольку открывается уже не ограниченная возможность использования 
«внешних» информационных процессов за счет всех предшествующих уровней и ступеней эволюции материи, что демонстрирует, например, возможное освоение информационных процессов на биологическом и квантовом уровнях.

Информационная сущность ноосферогенеза достаточно очевидна. На определенной ступени развития культуры как информационного продолжения процесса цефализации уже на уровне социальной ступени, как коллективного интеллекта цивилизации происходит становление информационной цивилизации. Переход к устойчивому развитию постепенно приводит к появлению информационно-экологической цивилизации. Информационная траектория «красной нитью» проходит через все этапы ноосферогенеза. Особенно выпукло культурно-информационная сущность ноосферогенеза проявляется в становлении коллективного ноосферно-опережающего интеллекта как естественного результата развития культуры. Эта целостная и самая грандиозная интеллектуальная система обретет способность кардинально усиливать информационные возможности человечества за счет наиболее рационального использования социокультурного и иного разнообразия.

Само название ноосфера - сфера разума на первый план выделяет не столько материальный компонент обсуждаемого здесь будущего глобального типа интеллекта, сколько духовноидеальные факторы. Вполне понятно, что идеальное не может существовать без материального, и ноосфера - это материально-идеальное образование, но главенствующим активным фактором выступает разум (а в перспективе и мудрость) в самых различных формах, но прежде всего - в его глобальном измерении и становлении. Конечно, идеальное появляется на определенном этапе развития материи, но опять-таки на другом, более позднем этапе развития идеальное, человеческий интеллект в его кол- лективно-глобальной форме должен занять приоритетные позиции, продвигаясь в «пространство мудрости», которая тоже может принять надиндивидуальный характер.

Этот этап социальной ступени эволюции материи, на котором судьбы материи во Вселенной «делегируются» ею порожденному общепланетарному (а в перспективе глобально-космическому) и общечеловеческому интеллекту, и имеет смысл связывать с ноосферой. Ноосфера будет представлять (в своем идеальном варианте) социоприродную систему, в которой планетарное опережающее управление реализуется нравственно-справедливом разумом человека и глобальным интегральным интеллектом, формируемым с помощью компьютерных и телекоммуникационных технологий (в том числе систем искусственного интеллекта и глобальной сети информационной связи).

Однако между пока гипотетическим глобально-ноосферным интеллектом и современным состоянием общественного сознания в его глобальном масштабе существует кардинальное противоречие. Движение от глобализации и информатизации к планетарно-целостному ноосферному интеллекту должно разрешить противоречие между принципиальной ограниченностью индивидуального (атомарного) интеллекта и объективными императивами перехода к цивилизации устойчивого развития. Этому последнему должен соответствовать принципиально новый тип интеллекта, обслуживающего не только интересы отдельного человека и ограниченных коллективов, но и всего человечества ради всеобщего выживания.

«Интеллектуальное» противоречие между нынешней и будущими моделями цивилизационного развития должно разрешаться в пользу формирования в ходе ноосферогенеза коллективно-целостного интеллекта всего человечества. Именно в этом и будет заключаться основ- 
ной интеллектуально-информационный процесс становления ноосферы, опирающийся и «накладывающийся» на переход к социоприродному устойчивому развития. Но это не означает, что развитию индивидуального интеллекта уже не должно уделяться внимание. Речь идет о гармонизации процессов развития личностной и коллективно-ноосферной форм интеллекта. Коллективному интеллекту, процессу формирования его глобально-космических форм должно быть уделено не меньшее внимание, чем индивидуальному, поскольку от этого зависит судьба всего человеческого рода, а не только отдельного человека. Переход же от индивидуального к коллективно-глобальному интеллекту во всей гамме социальных взаимодействий потребует существенного изменения ценностных ориентиров и формирования новых целей глобального развития. В современной модели социальноэкономического развития, как правило, принимают решения атомарные либо корпоративные субъекты, индивиды и группы (в свою пользу, а не в интересах выживания всего человечества). И лишь в последние десятилетия начал формироваться так называемый социальный (социально-технологический) интеллект, представляющий собой не общественное сознание в его традиционном понимании, а гибридный человеко-машинный интеллект, включающий в себя и естественный, и искусственный интеллект, и другие средства информатики.

Многие социоприродные тенденции окажутся в будущем составляющими общепланетарного и космизирующегося процесса - ноосферогенеза, который включает в себя и другие тенденции - информатизацию, интеллектуализацию, экологизацию, глобализацию, футуризацию и т.д. Однако среди всех этих тенденций наиболее существенное значение для формирования ноосферы имеют информатизация и интеллектуализация, поскольку они наиболее тес- но связаны с той важной тенденцией, которая направлена на изменение сознания человека и всего человечества. Если некоторые другие упомянутые выше составляющие, так или иначе, были ориентированы на преобразование природы, ее вещества и энергии, имели направленность от общества к окружающей его природной среде, то информатизация оказалась процессом трансформации информационно-интеллектуального мира человека, его сознания и мышления на всех уровнях - личностном, коллективном вплоть до созидания пока гипотетического «глобально-космического сознания», которое в перспективе ноосферогенеза должно будет обрести форму ноосферного интеллекта.

Конечно, было бы упрощением считать, что интеллектуализация как закономерность социального развития и перехода к ноосферной цивилизации тождественна процессу информатизации (на что нацеливает все большее использование использование термина «smart» в информационной сфере). Существуют и иные механизмы и факторы повышения уровня индивидуального и общественного сознания, другие виды духовного творчества. Однако с помощью средств информатики, особенно базирующихся на системах искусственного интеллекта, совокупное общественное сознание не просто повышается, а приобретает новое качество, делающее возможным выживание и дальнейшее существование человеческого рода. Происходит глубокая трансформация интеллектуального потенциала социосферы, что со временем может привести к превращению её в сферу разума.

Глобально-коллективный интеллект, соответствующий носфере, не может сформироваться в современной модели неустойчивого развития в силу ряда причин и, прежде всего, из-за атомарно-индивидуалистического принципа поведения человека в обществе и отсутствия необходимой целостности цивилизации (которая 
сформируется лишь на завершающей стадии глобализации через переход к устойчивому развитию). Однако от принципа выживания индивида в экономоцентрическом обществе необходимо переходить на принцип выживания всего человечества в благоприятной для него окружающей среде. Выживание человечества возможно лишь на пути повышения степени его «интеллектуально-информационной мудрости» благодаря объединению индивидуальных интеллектов в некоторую системную целостность с помощью средств информатики и всех используемых информационных процессов.

В условиях выживания человечества на пути становления ноосферы через устойчивое развитие необходимо формирование принципиально нового типа интеллекта, который, с одной стороны, воплощал бы все позитивные качества интеллекта индивида, а с другой, - носил бы планетарно-интегративный, надиндивидуальносинергетический характер, расширившись до глобально-космических масштабов, реализуя не только новые типы разумности и рациональности, но и черты и императивы мудрости.

Основная идея создания ноосферного интеллекта - повысить степень системности, достоверности, обоснованности и превентивности принимаемых всем мировым сообществом решений, принимая во внимание интересы не только нынешних, но и будущих поколений (и в какой-то степени сохранения биосферы в целом). Это невозможно реализовать лишь на уровне индивидуальных интеллектов ныне существующих поколений. Необходима их дальнейшая «интегративная рационализация» вплоть до формирования общецивилизационной и даже «социоприродной» рациональности (эта рациональность не будет только научной, а более широкой и интегративно-деятельностной). Вполне понятно, что во имя выживания всего человечества приходится выделять в ка- честве приоритетного наиболее эффективные рациональные механизмы выживания и движения по пути устойчивого развития ноосферной ориентации. В перспективе важно исследовать связь таких форм рациональности с нерациональными факторами (инстинктом, верой, волей и т.д.), от которых также зависит переход к сфере разума, особенно в начальный период перехода к устойчивому развитию, когда, например, демографический или религиозный факторы могут оказаться решающими. И, конечно, важно проанализировать возможность становления нового типа - «глобальной мудрости», который может стать идеалом для последующих форм ноосферогенеза.

Становление ноосферы - это не только выдвижение нравственно-гуманистического индивидуального и коллективного разума на приоритетное место в развитии общества, но и обретение им новых качеств, которыми ранее существующие формы «бытия разума» не обладали (например, появление системно-гибридного ноосферного интеллекта). Сейчас же мировая цивилизация имеет разнонаправленную динамику своих эволюционных тенденций, сочетание позитивных и негативных процессов. И всё же пока превалируют негативные процессы - человечество неуклонно движется к своему самоубийственному финалу - глобальной социальноэкологической катастрофе - и в этом трагическое противоречие неустойчивого развития.

Понимание будущей цивилизации ноосферы, в которой основной составляющей станет ноосферный интеллект как интегральное сознание всего человечества было присуще той ноосферной концепции, которую, следуя В.И. Вернадскому, развивал Н.Н. Моисеев. Этот ученый говорил о Коллективном Разуме (Интеллекте), полагая, что: «разум человека - это системное свойство совокупности нейронов его мозга, а Коллективный Разум - системное свойство со- 
вокупности индивидов, обладающих разумами и возможностью обмена информацией. Разум отдельного человека в системе Коллективного Разума подобен нейрону в мозгу человека» (Моисеев 1993: 48). Причем развитие этого типа интеллекта во временном отношении Н.Н. Моисеев связывает со становлением человеческого общества, а сверхбыстрое, лавинообразное развитие Коллективного Разума - с развитием средств связи и новых информационных технологий. «Коллективный Интеллект, вооруженный технологией искусственного интеллекта, вот дальнейший путь развития информационной истории биосферы» (Моисеев 1993: 48). Он считал, что мы стоим на пороге становления Коллективного Общепланетарного Разума, который предоставляет определенный шанс человечеству сохранить себя в биосфере и во Вселенной.

Будущий глобально-коллективный интеллект ноосферы должен будет обрести свою «общепланетарную» разумность и в перспективе даже «глобальную мудрость», ведь мировое сообщество и каждый его субъект должны действовать как единое целое, переходя на новый тип цивилизационного развития. В созидании этой системной целостности интеллекта цивилизации и заключается одна из основных проблем и пока ещё слабо уловимых целей глобализации, которые остаются за пределами горизонта исследований, не ориентированных на столь далекие времена, когда станут проявляться первые очертания сферы разума и её выход «пространство мудрости».

Глобальная «коллективизация» разума с помощью средств информатики и планетарных средств коммуникаций преследует цель устранения отрицательных черт субъективизма, снятие ограниченности индивидуального сознания и повышение степени разумности и реализации нравственно-гуманистических ценностей человечества как будущего целостного социального организма за счет соединения интеллекта каждой личности в системное целое, обладающее новым качеством рациональности, которую именуют ноосферной рациональностью (а, может быть, более уместно это новое качество связывать с мудростью в её глобальном измерении).

Появятся новые качества этого планетарного интеллекта - в особенности свойство уже упомянутого «опережения», обеспечивая выживание человеческого рода и становление ноосферы в условиях сохранения природы. Вместе с тем «коллективизация» и информатизация интеллектуальных процессов должна привести в той или иной степени к формированию тех качеств, которые человечество будет относить к феномену мудрости, разумеется, в понимании его теми поколениями людей, которые будут создавать это новое пространство своей жизнедеятельности.

Процесс «коллективизации» интеллекта здесь принципиально иной, чем все известные виды и формы коллективизации, осуществляемые по тому или иному стандарту и сводящие все к универсально-бюрократическому однообразию. Вот почему термин «коллективизация» неточно отражает саму идею объединения и гармонизации сознаний индивидов (и их корпоративных форм) и интеллектуальных средств информатики. Ноосферный интеллект - это, в отличие от прошлого, и индивидуальное сознание, включенное в общий банк знаний, и интегральные алгоритмы переработки информации, и взаимодействие интеллекта всех нормальных индивидов. В нем возникает синергетический эффект целостности от планетарного объединения знания индивидов и информации технических средств, дающий возможность с помощью новых информационных технологий, включая искусственный интеллект, принятия мудрых опережающих решений и глобально-когерентного 
управления переходом к ноосферной цивилизации.

Здесь, говоря о «коллективизации разума», дающей синергийно-кооперативный эффект, имеется в виду принципиально новая закономерность, которая должна отличаться от ранее описанной, когда в процессе глобализации знания, мнения или решения, происходила утрата информационного содержания. Собственно говоря, подобная утрата аналогична действию закона увеличения энтропии, а нам опять-таки придется прибегнуть к идеям синергетики, которая показывает как появляется в результате самоорганизации так называемый синергетический эффект при создании из хаоса упорядоченных и устойчивых структур. И вместе с тем синергетика рассматривает вопросы, как в неустойчивом и динамично меняющемся природном и социальном мире эти структуры могут устойчиво существовать, особенно на супермагистрали глобальной эволюции.

Одна из важных идей формирования ноосферного интеллекта заключается в том, чтобы создать глобальную интеллектуально-информационную систему, которая могла бы управлять дальнейшим процессом самоорганизации цивилизационного процесса, решая все те сложные проблемы, которые уже стоят и появятся в будущем. С точки зрения решения социально-экологических проблем будущий ноосферный интеллект должен выполнять функции, аналогичные тем, которые реализует биосфера, стабилизирующая и регулирующая себя и окружающую среду с помощью биоты, и в то же время, продолжающая естественным образом эволюционировать. Устойчивость биосферы обеспечивается огромным биологическим разнообразием (информационным содержанием), выполняющим регулятивно-стабилизирующие компенсаторно-релаксационные функции. Здесь также реализуется кибернетический закон необходимого разно- образия У.Эшби, и биота выполняет работу по поддержанию условий окружающей среды, «устраивающих» живые системы, которые синергетическим образом скоррелированы между собой для управления окружающей средой при помощи биохимического круговорота биогенов (Лосев 2003: 83). Однако действие биотической системы регуляции окружающей среды происходит в определенных пределах, превышение которых со стороны внешних воздействий (когда превышение разнообразия этих воздействий на биосферу больше ее внутреннего информационного содержания) ведет к потере устойчивости и разрушению биосферы.

Нечто подобное, но уже для человечества должен реализовать ноосферный интеллект, выполняя функцию адаптации человечества к биосфере и экологизируя хозяйственную и иную деятельность. Однако здесь нельзя ограничиваться лишь указанием на адаптацию (хотя это сейчас наиболее важно) цивилизации к биосфере, так как социуму присуща и адаптирующая функция, которую в принципе нельзя устранить или полностью вписать в экосистемы и даже в биосферу. Это нашло свое отражение в наличии двух основных видов производств - индустрии и сельского хозяйства. Если это последнее хозяйство в принципе можно вписать в биосферу, переходя на адаптивную стратегию интенсификации, то индустрия и создаваемые ею селитебно-урбанизированные ландшафты в принципе не могут реализовать «стратегию адаптации» к биосфере, оставаясь для биоты ксенобиотическим фактором и процессом.

Превращение человечества в ноосферную цивилизацию предполагает, что культура как информационный феномен станет решающим фактором дальнейшего развития социальной ступени эволюции. Культурно-информационная сущность ноосферогенеза особенно четко проявится в становлении ноосферного интеллекта 
как естественного развития культуры на новом более высоком этапе её развития. Ноосферный интеллект соединит в одну целостную социотехнологическую систему культуру как коллективный интеллект цивилизации, естественный интеллект отдельных личностей и искусственный интеллект новых информационных технологий.

Эта целостная и самая грандиозная информационно-интеллектуальная система обретет способность кардинально увеличить информационные возможности человечества за счет наиболее рационального использования накопленного социокультурного разнообразия. И хотя мы имеем в виду целостный интеллект ноосферной цивилизации, тем не менее, речь должна идти и о своего рода «социоприродном» интеллекте как важного продолжения его «социальной компоненты». Следует согласиться с В.Келле, что «ноосфера - это не только разумное устройство человеческого общества, но и ответственность человека за разумное преобразование природы, за состояние природной среды» (Келле 2001: 129).

Поэтому в будущем ноосферном интеллекте должны быть информационные блоки, отвечающие за состояние и развитие общества и за состояние окружающей среды, ее взаимодействие с природой. Т.е. с экологической точки зрения ноосферный интеллект будет функциониро-

\section{ЦИТИРОВАННАЯ И УПОМЯНУТАЯ ЛИТЕРАТУРА}

1. Вайцзеккер, Э., Ловинс, Л., Ловинс, Э. (2000). Фактор четыре. Затрат - половина, отдача - двойная. Новый доклад Римскому клубу/ Пер. с англ. Москва: изд-во «Academia».

2. Вернадский, В. (1991). Научная мысль как планетное явление. Москва: изд-во «Наука». вать в более широкой «системе координат», выходя в социоприродное измерение, что увеличит шансы цивилизации на существование в благоприятных для нее природных условиях, обеспечивая ее безопасность через ноосферогенез как форму и этап глобально-эволюционного процесса.

Сфера разума не может появиться стихийно, хотя существуют и проявляются определённые ноосферные тенденции и в современной мировой цивилизации. В результате трансформации социосферы в ноосферу появится ноосферный интеллект как принципиально новая форма «общественного сознания», объединяющая интеллектуальные ресурсы человечества и средства информатики, использующая опережающие механизмы для реализации желаемых вариантов социоприродного развития. Очевидно, что одно из важных качеств этого интеллектуального фактора будет заключаться в их темпоральных характеристиках. Общественное сознание в прошлой и современной социосфере значительно отстает от социального и социоприродного бытия, запоздало отражая его и позволяя ему развиваться стихийно. В ноосфере же целостно-планетарный интеллект получает возможность предвидеть это бытие, прогнозируя и проектируя желаемое будущее.

3. Вернадский В. (2004). Биосфера и ноосфера. Москва: изд-во «Наука».

4. Ильин, И., Урсул, А. (2013). «В. Вернадскийосновоположник глобальных исследований». Вестник Московского университета. Серия XXVII. Глобалистика и геополитика. Москва. № 1.

5. Кант, И. (1965). Соч., т. 4, ч. 1, Москва: издво «Мысль».

6. Келле, В. (2002). «К проблеме ноосферы». Философские науки. Москва. № 5. 
7. Ллойд, С. (2013). Программируя Вселенную: Квантовый компьютер и будущее науки. Пер. с англ. Москва: изд-во «Альпина нонфикшн».

8. Лосев, К. (2003). «Биотическая регуляция окружающей среды». В сб.: Глобалистика. Энциклопедия. Москва: изд-во «Радуга».

9. Моисеев, Н. (1993). Восхождение к разуму. Лекции по универсальному эволюционизму и его приложениям. Москва: изд-во «Аспект Пресс»,.

10. Назаров, В (1993). Феноменология мудрости: Образы мудреца в истории культуры (нравственно-философское исследование). Тула: изд-во ТГПИ им. Л.Н. Толстого.

11. Прозоров, Л. (2012). «Было ли учение Вернадского о ноосфере?». Пространство и время. № 4.
12. Тейяр де Шарден, п. (1987). Феномен человека. Москва: изд-во «Наука».

13. Урсул, А. (2011). «Информация и культура». Философия и культура. № 1.

14. Урсул, А. (2013). «Мыслитель глобальной эпохи (К 150-летию со дня рождения В. Вернадского)». NB: Философские исследования. № 9.

15. Урсул, А. (1972). Отражение и информация. М.: Изд-во «Мысль».

16. GEO-5. (2012). Глобальная экологическая перспектива. Резюме для политиков. Найроби: Изд-во ЮНЕП.

УРСУЛ АРКАДИЙ

\section{ПЕРСПЕКТИВЫ СТАНОВЛЕНИЯ ГЛОБАЛЬНОГО ИНТЕЛЛЕКТА: ОТ СФЕРЫ РАЗУМА В ПРОСТРАНСТВО МУДРОСТИ}

\section{PEЗЮME}

В статье выстраивается единая эволюционно-информационная концепция становления ноосферы не только как планетарного феномена, но и как необходимого этапа вселенского процесса самоорганизации материи. Сфера разума представляется автором как ещё не существующее, а гипотетическое будущее состояние общества и его взаимодействия с природой, в котором приоритетное место будет занимать глобальный общечеловеческий ноосферный интеллект, направляющий социоприродную систему в безопасном направлении поступательной эволюции. Предполагается возможность более широкого понимания будущей области человеческого существования не просто как сферы разума, а как пространства, в котором будут воплощены идеалы и черты мудрости.

Ключевые понятия: глобальная эволюция, информация, культура, мудрость, ноосфера, ноосферный интеллект. 


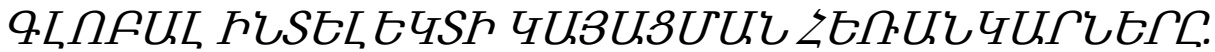 \\ คUとUчUน}

\section{$U U \Phi \cap \Phi \cap \kappa U$}

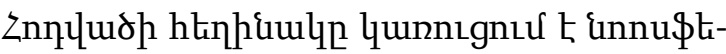

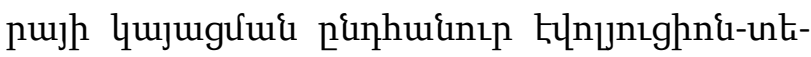

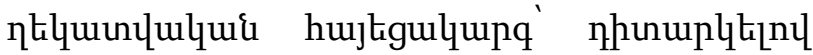

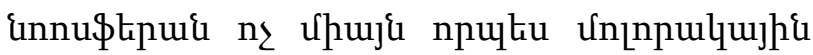

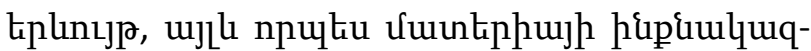

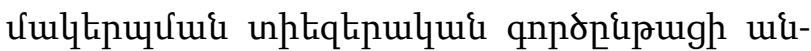

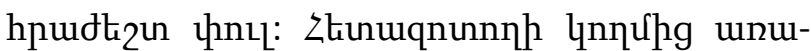

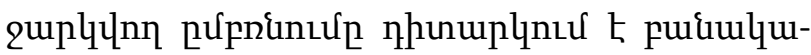

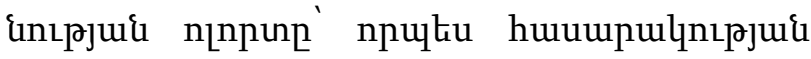

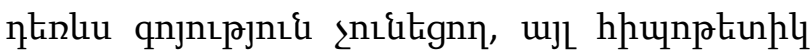

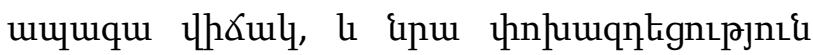
punıpjui htin, npnıu unugiuujhi nhpp Ł qpu-

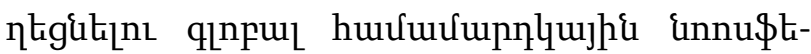

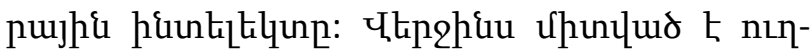

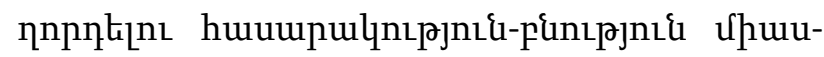

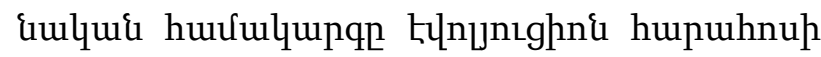

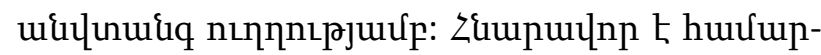

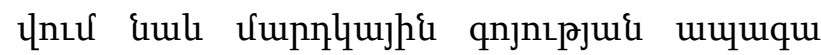

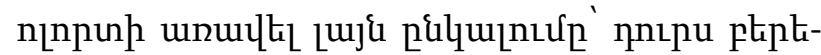

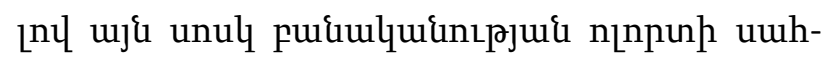

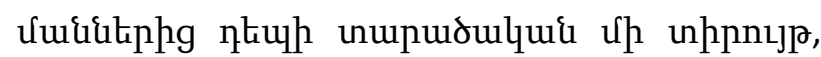

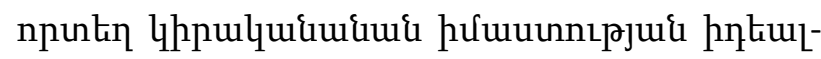

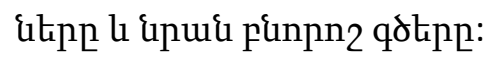

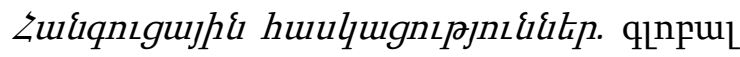

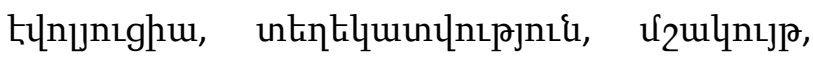

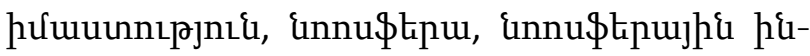
untliliun:

URSUL ARKADIY

\section{PROSPECTS FOR THE FORMATION OF THE GLOBAL INTELLIGENCE: FROM THE NOOSPHERE IN SPACE OF THE WISDOM}

\footnotetext{
SUMMARY

The paper builds a single evolutionary concept formation and information of the noosphere, not only as a planetary phenomenon, but as a necessary step in the universal process of self-organization of matter. Sphere of mind seems like the author does not yet exist, and the hypothetical future state of society and its interaction with nature, in which priority will occupy the global noosphere common human intelligence guiding socio-natural

system in a safe direction of progressive evolution. Suspected of a broader understanding of future human existence not simply as a sphere of reason, but as a space in which to be embodied the ideals and traits of wisdom.

Key concepts: global evolution, information, culture, wisdom, noosphere, noosphere intelligence.
} 